\section{Effects of melatonin on liver and} lung tissues of animals with bile duct ligation-induced hepatopulmonary syndrome

\author{
Adriane Dal Bosco 1,2,8, Josieli Raskopf Colares ${ }^{1,2}$, Sílvia Bona ${ }^{1,2}$, \\ Lívia Barboza De Andrade ${ }^{3}$, Luiz Alberto Forgiarini Jr. ${ }^{4}$, Aline \\ Felicio Bueno ${ }^{8}$, Alexandre Simões Dias ${ }^{1,3,7 *}$ and Norma Anair \\ Possa Marroni ${ }^{1,2,6}$
}

\author{
${ }^{1}$ Experimental Research Center, Hospital de Clinicas de Porto Alegre, Ramiro Barcelos, Porto \\ Alegre, RS, Brazil \\ ${ }^{2}$ Postgraduate Program in Medical Sciences, Federal University of Rio Grande do Sul, Ramiro \\ Barcelos, Porto Alegre, RS, Brazil \\ ${ }^{3}$ Postgraduate Program in Pneumological Sciences, Federal University of Rio Grande do Sul, \\ Porto Alegre, RS, Brazil \\ ${ }^{4}$ LaSalle University, Porto Alegre, RS, Brazil \\ ${ }^{5}$ Postgraduate Program in Biological Sciences, Physiology, Federal University of Rio Grande do \\ Sul. Sarmento Leite, Porto Alegre, RS, Brazil \\ ${ }^{6}$ Posgraduate Program in Cell and Molecular Biology Applied to Health, Universidade Luterana do \\ Brasil, Canoas, RS, Brazil \\ ${ }^{7}$ Postgraduate Program in Human Movement Sciences, Federal University of Rio Grande do Sul, \\ Porto Alegre, RS, Brazil \\ ${ }^{8}$ Methodist University Center, IPA, Brazil
}

\author{
More Information \\ *Address for Correspondence: \\ Alexandre Simões Dias, Doutor Pio Angelo 237, \\ Ipanema, Zip-code: 91760-300, Porto Alegre/RS, \\ Brazil, Email: asdias@ufrgs.br; \\ asdias@hcpa.edu.br; \\ alinefeliciobueno@gmail.com \\ Submitted: September 28, 2021 \\ Approved: October 12, 2021 \\ Published: October 13, 2021 \\ How to cite this article: Bosco AD, Colares JR, \\ Bona S, De Andrade LB, Forgiarini LA Jr., \\ et al. Effects of melatonin on liver and lung \\ tissues of animals with bile duct ligation-induced \\ hepatopulmonary syndrome. J Pulmonol Respir \\ Res. 2021; 5: 097-105.
}

DOI: 10.29328/journal.jprr.1001033

ORCiD: orcid.org/0000-0002-0609-4779

Copyright: ๔ 2021 Bosco AD, et al. This is an open access article distributed under the Creative Commons Attribution License, which permits unrestricted use, distribution, and reproduction in any medium, provided the original work is properly cited.

Check for updates

OPEN ACCESS

\title{
Summary
}

The objective was to assess the antioxidant effect of melatonin (MLT) on liver and lung tissues of animals with bile duct ligation (BDL)-induced hepato-pulmonary syndrome (HPS). A model of BDL-induced biliary cirrhosis was used in male Wistar rats. Results suggest that MLT has an antioxidant effect on liver and lung tissues in animals with BDL-induced HPS by higher activity of antioxidant enzymes in the group HPS treated with MLT and the histological analysis of lung parenchyma showing decreased damage in this same group, including other analysis described below.

\section{Introduction}

Hepatopulmonary syndrome (HPS) is characterized by a combination of liver disease, gas exchange abnormalities, and pulmonary vascular dilation [1]. Intrapulmonary vascular dilation causes arteriovenous pulmonary changes leading to reduced arterial oxygenation [2]. These changes occur due to vasodilation of the pulmonary capillaries, difficulting gas exchange, reducing the partial pressure of arterial oxygen, and causing in patients dyspnea and increased respiratory rate. Experimental models of secondary biliary cirrhosis induced by prolonged bile duct obstruction showed that this condition leads to acute inflammatory reactions and subsequently to systemic changes [3].
HPS interferes with the physiological functioning of hepatic and pulmonary systems and thus contributes to the worsening of patient's clinical status. This finding has already been reported by Oded, et al. who investigated the clinical status of patients with cystic fibrosis and portal hypertension [4].

Studies using experimental models of bile duct ligation (BDL) found that pulmonary vascular dilatation that characterizes HPS may result from autophagy promoted by pulmonary tissue cells responsible for accelerating the formation and proliferation of pulmonary macrovascular endothelial cells. One of the stimuli that cause pulmonary alteration is related to the release of inflammatory factors, such as tumor necrosis factor alpha (TNF- $\alpha$ ) and endothelin-1 (ET-1). 
The binding of ET-1 to its receptor activates pulmonary endothelial nitric oxide synthase (eNOS), leading to excessive production of nitric oxide (NO), a natural vasodilator. Bacterial translocation and subsequent accumulation of pulmonary macrophages result in the production of inflammatory cytokines, which contribute to NO-mediated vasodilation through increased expression of induced nitric oxide synthase (iNOS).This mechanism aims to remove organelles that were damaged in the pathophysiological process caused by liver disease $[5,6]$.

Oxidative stress has a key role in the progression and maintenance of several diseases, meaning that the administration of antioxidants may contribute to reduce hepatic and pulmonary changes. This was observed in experimental studies using a BDL model of HPS and antioxidant therapy $[7,8]$. Although melatonin (MLT) is usually associated with control and treatment of circadian rhythm changes, in recent years it has been much investigated for its antioxidant capacity in several tissues [9].

Liver tissue changes resulting from BDL-induced cirrhosis and the effect of melatonin were analyzed in the study by Colares, et al. which observed improvements in parenchymal structure and in liver function after the use of melatonin [10]. The effect of antioxidants such as quercetin and S-nitroso-Nacetylcysteine (SNAC) on HPS has been studied elsewhere [11-13], but the effect of melatonin on lung tissue has not been described in the literature yet.

In a review by Tan, et al. MEL was found to be more efficient in reducing oxidative/nitrosative stress compared with other antioxidants like vitamins C and E [9]. In cells, MLT is for gene regulation of genes and nuclear factors contributing to the formation and regulation of antioxidant enzymes [14]. It also contributes to the clinical treatment of several diseases [15], however, the results and mechanisms of this treatment are still controversial in the literature, depending on the tissue being evaluated. Thus, the action of MLT on liver and lung diseases such as HPS, especially its antioxidant effect, requires further study.

The aim of this study was to evaluate the antioxidant effect of MLT on liver and lung tissues in animals with BDL-induced HPS.

\section{Material and methods}

An experimental study was conducted with 24 male Wistar rats with a mean weight of $250 \mathrm{~g}$ and from the Animal Experimentation Unit at Hospital de Clínicas de Porto Alegre. They were maintained on a $12: 12 \mathrm{~h}$ light/dark cycle, at a temperature of $22+2 \stackrel{\circ}{ } \mathrm{C}$, at a relative air humidity between $40 \%-60 \%$, and were given water and standard rat feed ad libitum.

A model of secondary biliary cirrhosis was used according to that established by Kountouras [16], based on bile duct ligation (BDL). The sample was divided into four groups of six animals each. Group 1: Control group (CG) - a simulation of BDL was performed and vehicle solution - sodium chloride ( $\mathrm{NaCl} 0.9 \%)$ - was administered intraperitoneally (i.p.). Group 2: Control group + melatonin (CG+MLT) - a simulation of BDL was performed and MLT was administered i.p. (20 $\mathrm{mg} / \mathrm{kg}$ of body weight). Group 3: Hepatopulmonary syndrome (HPS) was performed and vehicle solution - sodium chloride ( $\mathrm{NaCl} 0.9 \%)$ was administered i.p. Group 4: Hepatopulmonary syndrome + melatonin (HPS+MLT) - BDL was performed and MLT was administered i.p. (20 mg/kg of body weight).

After fourteen (14) days of BDL the animals received the vehicle or MLT according to the group and after fourteen (14) days of treatment were anesthetized to collection of blood and lung, liver, and femur tissues, totaling twenty-eight (28) days of experiment. Blood samples collected by retro-orbital venous plexus puncture were used to assess liver function by measuring the levels of the following enzymes: aspartate aminotransferase (AST), alanine aminotransferase (ALT), and alkaline phosphatase (AP). Analyses were performed using an automated enzymatic method (Siemens Advia 1800 Chemistry System). AST and ALT levels were determined by the Kinetic UV test, and AP levels were determined by a colorimetric kinetic enzyme assay.

The vehicle solution or MLT started to be administered 14 days after the surgical procedure, with MLT (SIGMA ${ }^{\circledR}$ Chemical Co St Louis, Mo) being administered i.p. (20 mg/kg) at a volume proportion of $0.6 \mathrm{~mL}$ daily for 14 days.

After being collected, tissues were weighed and placed in a $9 \mathrm{~mL}$ phosphate buffer per gram of tissue, then homogenized with Ultra-Turrax (IKA-WERK) for 2 minutes at a temperature of $0-2 \stackrel{\circ}{\circ}$, and finally homogenized and centrifuged in a refrigerated centrifuge (SORVALL RC-5B Refrigerated Superseed Centrifuge) for 10 minutes at 4,000 revolutions per minute (rpm) [17].

Lipoperoxidation (LPO) was measured through the quantitative thiobarbituric acid-reactive substances (TBARS) method, in which the colored product obtained was collected and read in a spectrophotometer (CARY 3E - UV - Visible Spectrophotometer Varian) at $535 \mathrm{~nm}$. TBARS levels were expressed in $\mathrm{nmol} / \mathrm{mg}$ of protein [18].

Catalase (CAT) enzyme activity was determined using the method proposed by Boveris and Chance [19], and superoxide dismutase (SOD) activity was determined using an assay based on the ability of SOD to inhibit the formation of adrenochrome, a product resulting from the oxidation of adrenaline [20].

Glutathione peroxidase (GPx) is an enzyme that catalyzes the reaction of hydroperoxide with reduced glutathione (GSH), yielding oxidized GSH (GSSG) and the product of hydroperoxide reduction. Its activity may be determined by measuring the consumption of nicotinamide adenine 
dinucleotide phosphate (NADPH) when reducing GSSG to GSH [21].

The glutathione S-transferase (GST) activity assay is based on an enzyme reaction which at $30^{\circ} \mathrm{C}$ catalyzes the formation of $1 \mu \mathrm{mol}$ DNP-SG using a GSH concentration of $1 \mathrm{mmol} / \mathrm{L}$ and chloro dinitrobenzene (CDNB). The enzyme activity was measured spectrophotometrically at $340 \mathrm{~nm}$ and expressed as $\mu \mathrm{mol} / \mathrm{min} / \mathrm{mg}$ protein [22].

Nitric oxide production was indirectly measured with a quantitative Griess colorimetric assay, which is based on enzymatic reduction of nitrates $\left(\mathrm{NO}_{3}\right)$ to nitrites $\left(\mathrm{NO}_{2}\right)$ in the presence of nitrate reductase and NADPH, with subsequent colorimetric determination of $\mathrm{NO}_{2}$ by the Griess reagent (a mixture of sulphanilamide and naphthylethylenediamine specific for $\mathrm{NO}_{2}$ ). Because excess NADPH inhibits the Griess reaction, it is necessary to oxidize all NADPH that was not used in the reduction of $\mathrm{NO}_{3}$. This was achieved by adding nitrate reductase. The reading was performed in a microplate reader at $540 \mathrm{~nm}$ and results were expressed in $\mathrm{mmol}$ of $\mathrm{NO}_{2} /$ $\mathrm{NO}_{3}[23]$.

Cytokine levels were determined with the enzymelinked immunosorbent assay (ELISA) method (Read-SETGo, eBioscience, San Diego, USA). Interleukin-1 $\beta$ (IL-1 $\beta$ ) was expressed in $\mathrm{pg} / \mathrm{mL}$, as described previously [24].

SOD, inducible nitric oxide synthase (iNOS), and activation of nuclear factor kappa B (NF-kB) were assessed using Western blot analysis, as described by Laemmli, et al. [25] and Towbin, et al. [26]. Nuclear extracts were prepared from lung homogenates and the supernatant was collected and stored at $-80{ }^{\circ} \mathrm{C}$. Lysate proteins were fractioned by sodium dodecyl sulfate-polyacrylamide gel electrophoresis (SDS-PAGE) and transferred to polyvinylidene fluoride (PVDF) membranes. The membranes were then blocked with $5 \%$ nonfat dry milk in Tris-buffered saline containing $0.05 \%$ Tween 20 (TTBS) for $1 \mathrm{~h}$ at room temperature and probed overnight at $4{ }^{\circ} \mathrm{C}$ with anti-NF-kB/p65 (SC8008/65kDa) antibodies (Santa Cruz Biotechnology, Santa Cruz, CA, USA) at 1:200-1,000 dilution with TTBS in 5\% nonfat dry milk and with anti- $\beta$-actin (A5060/42kDa) antibodies (Sigma Aldrich, St Louis, MO, USA) at 1:2,000 dilution with TTBS in 5\% nonfat dry milk. After washing with TTBS, the membranes were incubated for $1 \mathrm{~h}$ at room temperature with anti-IgG-horseradish peroxidase (HRP) antibodies (Santa Cruz Biotechnology, Santa Cruz, CA, USA) at 1:4,000 dilution.

Proteins were detected using an enhanced chemiluminescence (ECL) commercial kit (Amersham Pharmacia Biotech, Little Chalfont, UK), membranes were exposed for 2 min, bands were quantified by densitometry using the Scion Image 4.02 for Windows (Scion Corporation, Frederick, USA), and results were expressed in arbitrary units (a.u.).

Hematoxylin and eosin (HE) and picrosirius red staining were used for histological examination of the lung. The diameter of blood vessels and the degree of fibrosis in lung tissues were assessed.

Samples for arterial blood gas analysis were collected from abdominal aorta to evaluate the following variables: potential of hydrogen $(\mathrm{pH})$, partial pressure of carbon dioxide $\left(\mathrm{PCO}_{2}\right)$, partial pressure of oxygen $\left(\mathrm{PaO}_{2}\right)$, carbonic acid $\left(\mathrm{HCO}_{3}\right)$, and oxygen saturation $\left(\mathrm{SpO}_{2}\right)$. Gas analysis was performed by iontophoresis using an ABL 700 analyzer (Radiometer, Copenhagen).

All animals were killed by exsanguination under deep anesthesia and then lung tissue was taken for analysis.

The comet assay was used to analyze the index and frequency of DNA damage as described by Speit and Hartmann [27], including changes suggested by Picada, et al. [28]. Damage index (DI) may range from 0 (completely undamaged, 100 cells $\times 0$ ) to 400 (maximum damage), and the damage frequency (\%) was calculated based on the number of cells with tail versus those with no tails [28].

Repeated-measures one-way analysis of variance (ANOVA) was used for intergroup comparison. Differences were assessed by the Student-Newman-Keuls procedure and data were analyzed using the Statistical Package for the Social Sciences (SPPS) version 17.0 or higher. The level of significance was set at $p<0.05$.

\section{Results}

Table 1 shows the results for hepatic enzymes (transaminase activity), lung tissue LPO, and activity of antioxidant enzymes and reveals the effects of MLT on the treated groups.

Figure 1 presents the results for $\mathrm{NO}_{2} / \mathrm{NO}_{3}$ ratio in lung tissue. The $\mathrm{NO}_{2} / \mathrm{NO}_{3}$ ratio and interleukin-1 $\beta$. levels were significantly increased in the HPS group compared with the CG and CG+MLT groups $(p<0.05)$ but decreased in the HPS+MLT group compared with the HPS group $(p<0.05)$.

The HPS group also showed a decrease in SOD and an increase in iNOS and p65 compared with the CG and CG+MLT groups ( $p<0.05)$, whereas the HPS+MLT group exhibited an increase in SOD and a decrease in iNOS and p65 compared with the HPS group $(p<0.05)$ (Figure 2 ).

Figure 3 shows that the diameter of pulmonary vessels was significantly increased in the HPS group compared with the CG and CG+MLT groups but significantly decreased in the HPS+MLT group compared with the HPS group $(p<0.05)$.

Histological analysis of lung tissue (Figure 4A) revealed preserved lung parenchyma with ventilated alveoli and alveolar septa. The HPS group exhibited tissue disorganization associated with increased vascular diameter and inflammatory 
Table 1: Activity of hepatic enzymes, lipid peroxidation, and antioxidant activity in lung tissue.

\begin{tabular}{|c|c|c|c|c|}
\hline Groups & CG & CG \pm MLT & HPS & HPS \pm MLT \\
\hline AST (U/L) & $82.25 \pm 9.31$ & $94.75 \pm 7.95$ & $444.50 \pm 48.12^{*}$ & $106.33 \pm 18.48^{\#}$ \\
\hline ALT (U/L) & $38.25 \pm 1.44$ & $36.75 \pm 2.53$ & $113.25 \pm 12.19^{*}$ & $38.67 \pm 0.76^{\#}$ \\
\hline AP (U/L) & $110.75 \pm 4.01$ & $106 \pm 5.94$ & $395.75 \pm 36.42^{*}$ & $97.67 \pm 10.80^{\#}$ \\
\hline TBARS & $0.38 \pm 0.05$ & $0.37 \pm 0.07$ & $0.83 \pm 0.07^{*}$ & $0.50 \pm 0.04^{*}$ \\
\hline CAT & $8.32 \pm 0.45$ & $9.09 \pm 0.36$ & $5.17 \pm 0.25^{*}$ & $8.52 \pm 0.40^{*}$ \\
\hline GST & $2.54 \pm 0.37$ & $2.08 \pm 0.39$ & $7.78 \pm 0.43^{*}$ & $3.95 \pm 0.70^{*}$ \\
\hline SOD & $4.37 \pm 0.38$ & $4.79 \pm 0.29$ & $1.99 \pm 0.19^{*}$ & $4.24 \pm 0.61^{\#}$ \\
\hline GPx & $6.68 \pm 0.23$ & $5.96 \pm 0.22$ & $3.21 \pm 0.12^{*}$ & $6.88 \pm 0.47^{\#}$ \\
\hline
\end{tabular}

Data expressed as mean \pm standard error. Experimental groups: Control group (CG), Control \pm melatonin group (CG \pm MLT), hepatopulmonary syndrome group (HPS), and hepatopulmonary syndrome \pm melatonin group (HPS \pm MLT)

AST- aspartate aminotransferase, ALT- alanine aminotransferase, AP- alkaline phosphatase

*Significant increase in the HPS group compared with the CG and CG \pm MEL groups $(p<0.001)$

\#Significant decrease in the HPS \pm MLT group compared with the HPS group $(p<0,001)$.

TBARS- thiobarbituric acid-reactive substances, CAT- catalase, GST- glutathione-S-transferase, SOD- superoxide dismutase, and GPx- glutathione peroxidase

*Difference in the HPS group compared with the CG and CG \pm MLT group; $p<0.01$.

"Difference in the HPS \pm MLT group compared with the HPS group; $p<0.001$.

Table 2: Arterial blood gas

\begin{tabular}{|c|c|c|c|c|}
\hline Groups & CG & CG \pm MLT & HPS & HPS \pm MLT \\
\hline $\mathrm{pH}$ & $7.37 \pm 0.04$ & $7.35 \pm 0$ & $7,24 \pm 0^{*}$ & $7.36 \pm 0.01^{\#}$ \\
\hline $\mathrm{PCO}_{2}$ & $45 \pm 1.41$ & $45 \pm 1.41$ & $56.66 \pm 1.51^{\text {** }}$ & $46.33 \pm 3.05^{\# \#}$ \\
\hline $\mathrm{PO}_{2}$ & $77 \pm 2.82$ & $73.50 \pm 0.7$ & $57.20 \pm 6.22^{\#}$ & $73 \pm 4.58^{\#}$ \\
\hline $\mathrm{HCO}_{3}$ & $25.95 \pm 0.91$ & $25.77 \pm 1.19$ & $26.48 \pm 0.96$ & $25.03 \pm 1.2$ \\
\hline $\mathrm{SpO}_{2}$ & $92 \pm 3.43$ & $92 \pm 1.41$ & $81.33 \pm 5.77^{\#}$ & $92.50 \pm 2.64^{\# \#}$ \\
\hline
\end{tabular}

Data expressed as mean \pm standard error.

Experimental groups: control group (CG), control group \pm melatonin ( $C G \pm M L T)$, hepatopulmonary syndrome (HPS) and hepatopulmonary syndrome \pm melatonin (HPS \pm MLT).

$\mathrm{pH}$ - potential of hydrogen, $\mathrm{PCO}_{2}$ - partial pressure of carbon dioxide, $\mathrm{PO}_{2}$ - partial pressure of oxygen, $\mathrm{HCO}_{3}$ - ion bicarbonate, $\mathrm{SpO}_{2}$ - oxygen periferic saturation

${ }^{*}$ Difference in $\mathrm{pH}$ between the HPS group compared with the $\mathrm{CG}$ and $\mathrm{CG} \pm \mathrm{MLT}, p<0.05$.

${ }^{*}$ Difference in $\mathrm{PCO}_{2}$ between the HPS group compared with the CG and $C G \pm$ MLT groups, $p<0.001$.

\#Difference in $\mathrm{PO}_{2}(p<0.01)$ and $\mathrm{SpO}_{2}(p<0.05)$ between the HPS group compared with the $\mathrm{CG}$ and $\mathrm{CG} \pm \mathrm{MLT}$ groups.

\#ifference between HPS \pm MLT and HPS groups, $p<0.05$.

Table 3: Comet assay in the different groups.

\begin{tabular}{|c|c|c|}
\hline Group & Damage index & Damage frequency \\
\hline CG & $68.6 \pm 26.3$ & $59.2 \pm 20.2$ \\
\hline CG \pm MLT & $72.9 \pm 16.8$ & $67.6 \pm 12.9$ \\
\hline HPS & $233.2 \pm 43.4^{*}$ & $96.8 \pm 4.6^{*}$ \\
\hline HPS \pm MLT & $117.7 \pm 20.3^{*}$ & $73.9 \pm 12.6^{*}$ \\
\hline
\end{tabular}

Data expressed as mean \pm standard error.

Experimental groups: Control group (CG), Control group \pm melatonin ( $C G \pm M L T$ ), hepatopulmonary syndrome group (HPS), and hepatopulmonary syndrome \pm melatonin ( $\mathrm{HPS} \pm \mathrm{MLT}$ )

${ }^{*}$ Significant increase in the HPS group compared with the CG and CG \pm MLT groups $(p<0.05)$.

\#Decrease in the HPS \pm MLT group compared with the HPS group $(P<0.05)$.

$\mathrm{NO}_{2} / \mathrm{NO}_{3}$

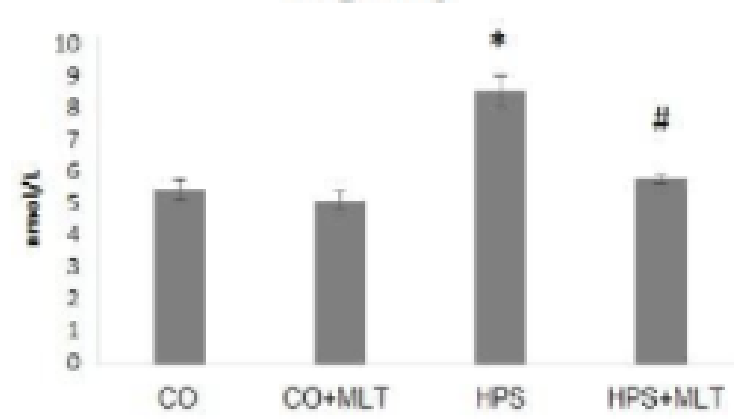

IL-1 $\beta$

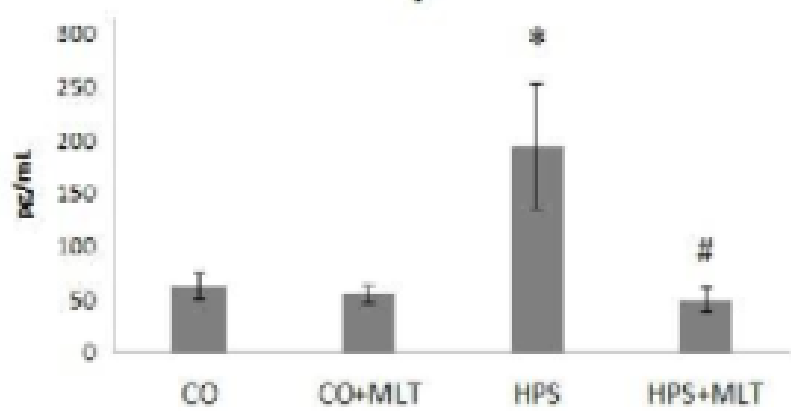

Figure 1: Nitrite/nitrate $\left(\mathrm{NO}_{2} / \mathrm{NO}_{3}\right)$ ratio and interleukin 1- $\beta$. Experimental groups: Control group (CG), Control group+Melatonin (CG+MLT), Hepatopulmonary syndrome group (HPS), and Hepatopulmonary syndrome+Melatonin group (HPS +MLT).

*Significant increase in the HPS group compared with the CG and CG + MLT groups $(p<0.05)$.

\#Significant decrease in the HPS+MLT compared with the HPS group $(p<0.05)$. 

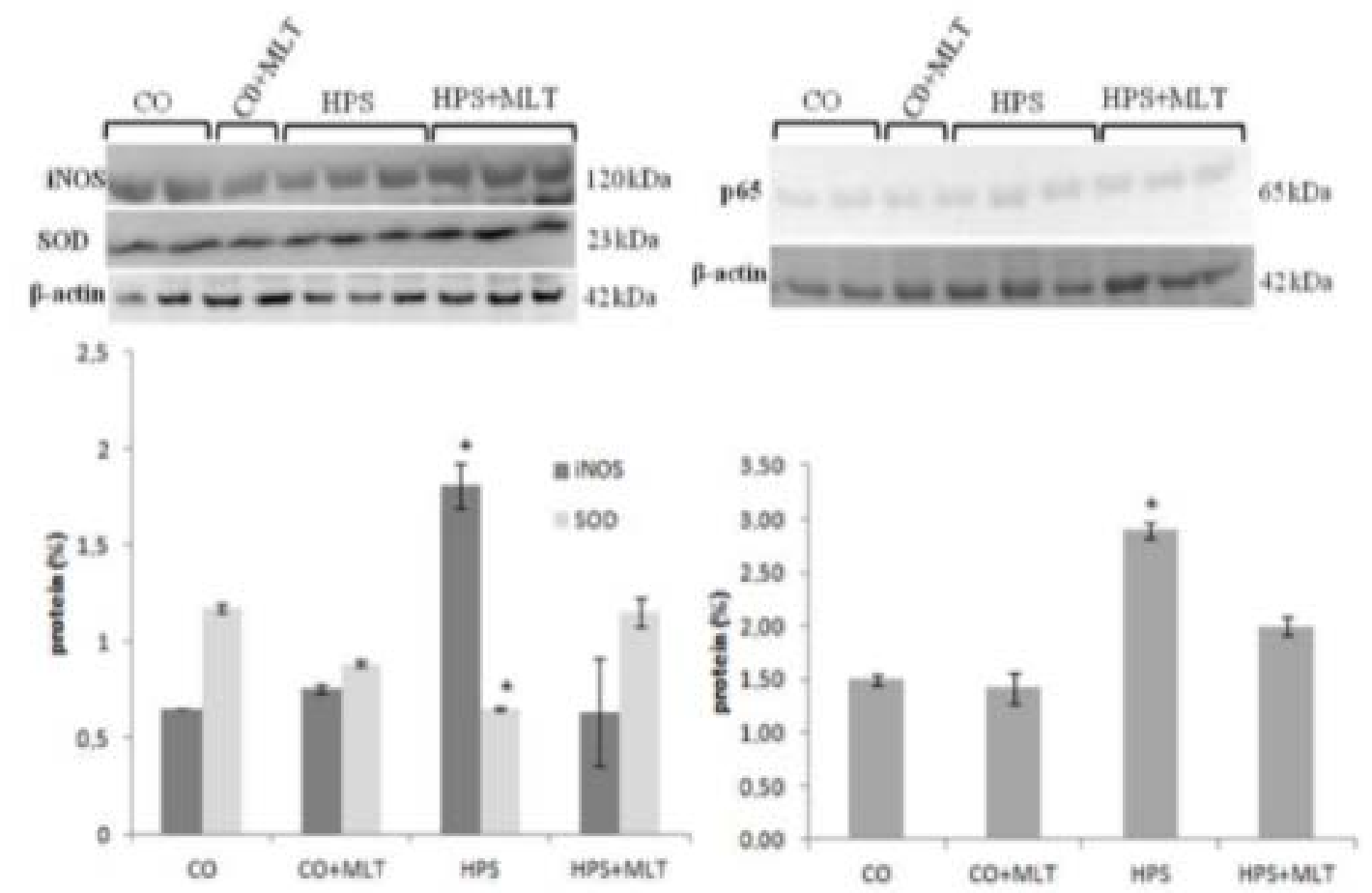

Figure 2: Western blot of superoxide dismutase (SOD), inducible nitric oxide synthase (iNOS), and p65.

*Significant increase compared with the CG and CG+MLT groups and significant decrease in the HPS group; $p<0.05$.
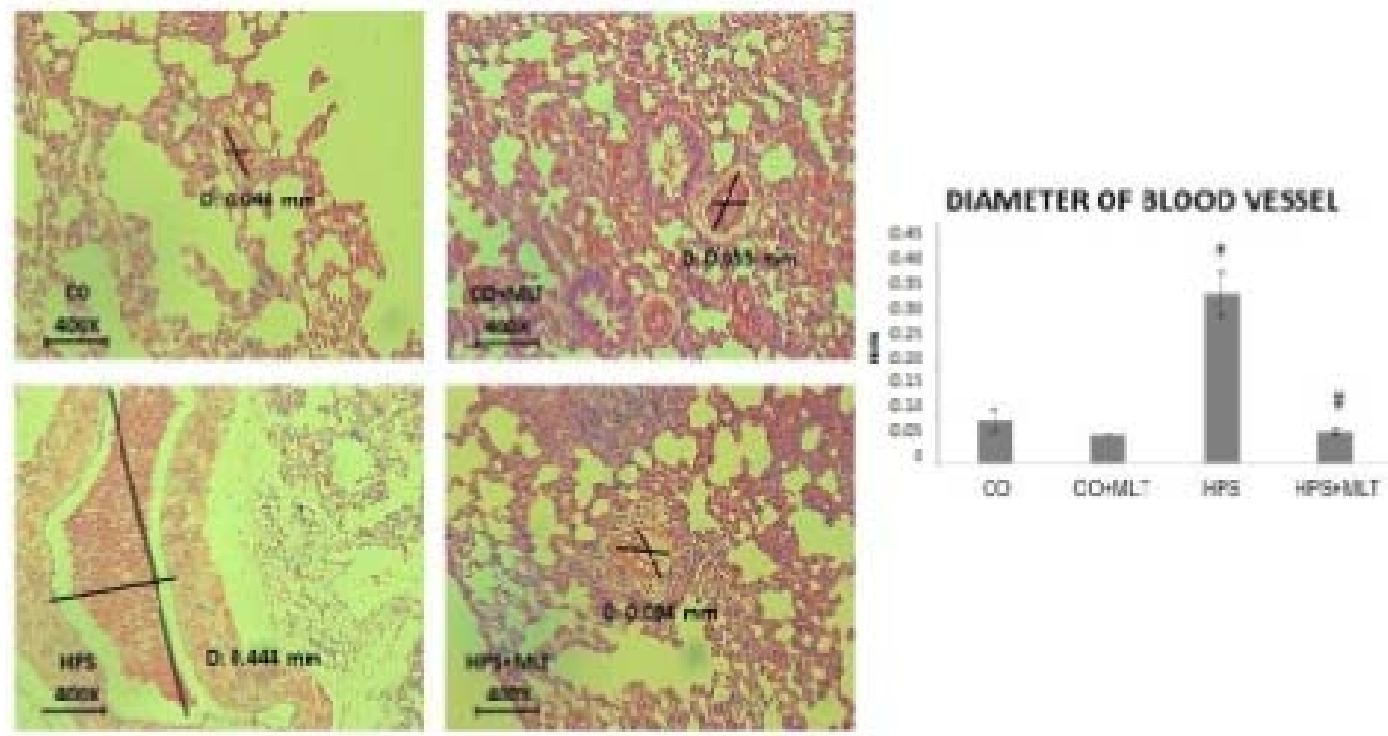

Figure 3: Photomicrograph of lung vascular diameter $(\mathrm{mm})$. Data expressed as mean + standard error.

Experimental groups: Control group (CG), Control+Melatonin group (CG+MLT), Hepatopulmonary syndrome (HPS) and Hepatopulmonary syndrome+Melatonin

(HPS+MLT).

*Significant increase in the HPS group compared with the CG and CG+MLT groups $(p<0.05)$.

"Significant decrease in the HPS+MLT group compared with the HPS group $(p<0.05)$.

infiltrate in lung parenchyma. Conversely, the HPS+MLT group showed tissue restructuring, similar to that of the CG and CG+MLT groups, but also presented with inflammatory infiltrates. Figure $4 \mathrm{~B}$ shows a photomicrograph of lung tissue sections evidencing increased pulmonary fibrosis in the HPS group compared with the CG and CG+MLT groups. This change was attenuated by treatment with MEL, since there was a decrease in pulmonary fibrosis in the HPS+MLT group compared with the HPS group.

Arterial blood gas analysis (Table 2 ) revealed a significant decrease in $\mathrm{pH}(p<0.05)$ and an increase in $\mathrm{PCO}_{2}(p<0.001)$ in the HPS group compared with the CG and CG+MLT groups, as well as a decrease in $\mathrm{PO}_{2}$ and $\mathrm{SpO}_{2}$ in the HPS group compared 
A
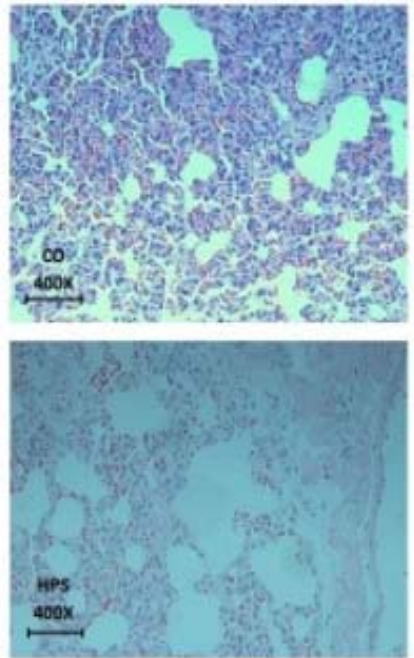

B
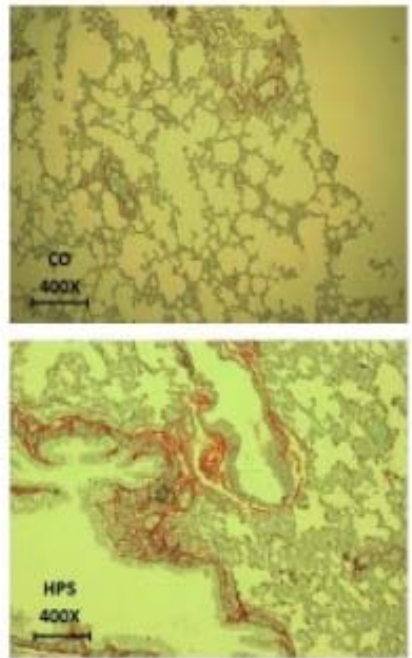
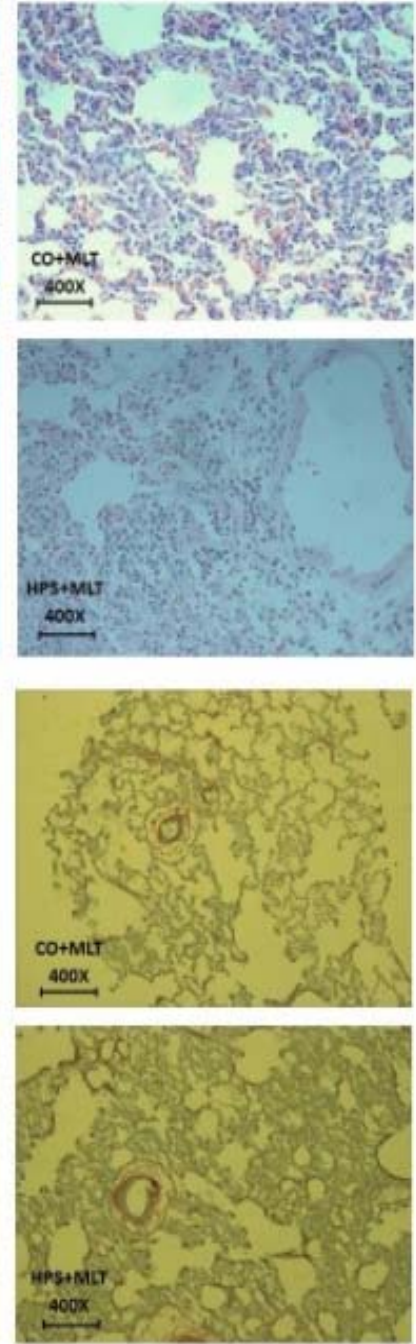

with the CG $(p<0.01)$ and the CG+MLT groups $(p<0.05)$. All these variables were improved in the HPS+MLT group $(p<0.05)$ compared with the HPS group.

Table 3 shows that damage index and frequency as determined by the comet assay were significantly increased in the HPS group compared with the CG and CG+MLT groups $(p<0.05)$ and significantly decreased in the HPS+MLT group compared with the HPS group $(p<0.05)$.

\section{Discussion}

This study was able to demonstrate the antioxidant and anti-inflammatory effect of MLT on liver and lung tissues, and our experimental model found a decrease in the index and frequency of DNA damage and reduced histological damage in lung parenchyma.

Using the same experimental model to assessed pulmonary alterations caused by BDL, Tieppo, et al. [29] found an increase in AST, ALT and AP activity and changes in lung parenchyma. These results were similar to those obtained in the present study, which found changes in hepatic enzymes and lung tissue, with improvements after treatment with MLT.

A study by Colares, et al. [10], using the same experimental model as ours showed that hepatic alterations observed in animals with HPS improved after treatment with MLT, but lung tissue was not assessed.

In chronic diseases affecting different organs such as liver, lung, and nervous system, it is possible to observe an increase in the amount of collagen and proteins in tissues composing these organs [30]. Oxidative stress as assessed by LPO promotes disorganization in cell membranes, with increased permeability and leakage of enzymes between intra- and extracellular media, leading to cell death [31]. In the present study, there was an increase in lung tissue LPO in the HPS group, but these levels were reduced in the HPS+MLT group.

The activity of the antioxidant enzymes CAT, SOD, and GPx had a significant decrease in the HPS group compared with the CG and CG+MLT groups, and an increase in the HPS+MLT group compared with the HPS group. However, glutathione- 
S-transferase (GST) showed an opposite behavior, with a significant increase in the HPS group and a decrease in the HPS+MLT group.

The antioxidant defense system, composed mainly of SOD, CAT and GPx, may be the responsible for this tissue response because this system neutralizes reactive oxygen species (ROS) due to its capacity of donating electrons [32].

Bona, et al. [33] showed the antifibrinogenic effect of MLT in the liver tissue, with improved oxidative stress, and inflammatory and angiogenic processes caused by liver cirrhosis experimentally induced by $\mathrm{CCl}_{4}$ in rats.

MLT is an indoleamine that has a potent antioxidant effect due to its chemical structure consisting of a double bond at carbons 2 and 3, thus protecting different tissues against the action of free radicals [34] and having an anti-inflammatory and immunomodulatory action [35].

We believe that, in our study, MLT was responsible for removing the reactive oxygen species (ROS) in lung tissue and for regulating antioxidant enzyme activity, exhibiting a similar effect to that observed in the liver tissue by Schemitt, et al. [36].

There was also an indirect increase in nitric oxide metabolism assessed by the ratio between nitrites and nitrates in the HPS group compared with the CG and CG+MLT groups and a decrease in the HPS+MLT group compared with the HPS group. A similar result was reported by Feng \& Hong [37], who evaluated vasoactive substances and hemodynamic anomalies in patients with HPS caused by chronic liver disease, with increased concentrions in the ratio between nitrites and nitrates and a negative correlation with vascular resistance in the pulmonary artery.

Arginine metabolism mediated by nitric oxide synthases, especially by endothelial nitric oxide synthase (eNOS), has an important participation in the production of endogenous nitric oxide (NO) and in circulating nitrate levels in the organism [38]. iNOS and eNOS contribute to the development of HPS through pulmonary vasodilation, and exhaled nitric oxide levels were also increased in patients with HPS [39].

Using an experimental model of carbon tetrachloride (CCl4), Bona, et al. [33] reported increased NF-kB and iNOS and increased nuclear expression of the p65 subunit. These findings were consistent with those of the present study, which demonstrated an increased iNOS in the HPS group and reduced iNOS in the HPS+MLT group. In agreement with the studies by Bona, et al. [33] and Mauriz, et al. [40], MLT promoted the modulation of NF-kB, thus enabling the control of the inflammatory process, as shown by the reduction in iNOS in the HPS+MEL group. The same occurred with interleukin $1-\beta$, which exhibited increased levels in the HPS group and reduced levels in the HPS+MLT group, corroborating findings by Kunak, et al. [41], although these authors evaluated the kidney tissue.

This mechanism may be explained by the action of phagocytic cells that act in the process of bacterial translocation occurring in the HPS, in which the migration of macrophages to the lung tissue leads to production of superoxide radical anion $\left(\mathrm{O}_{2}^{-}\right)$that binds to the nitric oxide produced by the iNOS. Increased enzyme antioxidant activity as observed by the significant increase in SOD expression in lung tissue homogenates in the HPS group may be a response to protect the tissue against aggression caused by increased ROS.

The histological analysis of the lung tissue performed in the present study revealed tissue disorganization in the HPS group, with increased vascular diameter and infiltrate area in lung parenchyma, with tissue restructuring and reduced vascular diameter in the HPS+MLT group. Vascular disorganization with arteriovenous shunt and pulmonary vasodilatation compromise the maintenance of adequate levels of arterial oxygen. In the HPS group, limited oxygen diffusion to capillary result from the presence of vascular bed dilation associated with increased cardiac output characteristic of hyperdynamic circulation in cirrhosis rather than from thickening of alveolarcapillary membrane [42].

Tieppo, et al. [7] found a decrease in $\mathrm{PaO}_{2}$ and $\mathrm{SatO}_{2} / \mathrm{Hb}$ and a significant increase in $\mathrm{PaCO}_{2}$ in cirrhotic animals compared with the CG. These findings corroborate those of the present study, arterial blood gas parameters $\mathrm{pH}, \mathrm{PaO}_{2}, \mathrm{PaCO}_{2}, \mathrm{SpO}_{2}$ were reestablished after treatment with MLT.

DNA changes may be assessed by micronucleus and comet assays, and this study found a significant increase in damage index and frequency in the HPS group and a reduction in animals treated with melatonin. In the study by Vercelino, et al. [43], there was an increase in the frequency of micronuclei in bone marrow and increased DNA damage in lung and liver tissues in animals from the HPS group, although damage could not be reversed at a dose of $10 \mathrm{mg} / \mathrm{kg}$ using treatment with S-NAC antioxidant, a fact that occurred in our study after the administration of melatonin.

A recent study published by Bomena, et al. [44] assessed the diagnostic accuracy of hepatopulmonary syndrome (HSP) in cirrhosis according to the International Classification of Diseases (ICD) for hepatopulmonary syndrome (HSP) in a large integrated health care system. The diagnosis of HPS by ICD code is made in an extremely small subset of a sizeable cirrhotic cohort. Studies to understand the pathophysiological processes can help clinical studies, as there is a difficulty in evaluating patients with SHP.

The results of the present study indicate that MLT has the capacity of improving oxidative stress, activity of the antioxidant enzymes CAT, SOD, GPX, and GST, SOD expression, 
inflammatory process, gas exchanges, vasodilation, DNA damage index and frequency, suggesting its use in clinical trials in patients with chronic liver disease diagnosed with HPS.

\section{Acknowledgment}

This study was supported by the Fund for Research and Event Promotion (FIPE)/Hospital de Clínicas de Porto Alegre (HCPA) and Laboratory of Experimental Hepatology and Gastroenterology (HCPA/UFRGS) e Laboratory of Oxidative Stress and Antioxidants (ULBRA).

\section{References}

1. Krowka MJ, Fallon MB, Kawut SM, Fuhrmann V, Heimbach JK, et al International liver transplant society practice guidelines: diagnosis and management of hepatopulmonary syndrome and portopulmonary hypertension. Transplantation. 2016; 100: 1440-1452. PubMed: https://pubmed.ncbi.nlm.nih.gov/27326810/

2. Koch DG, Fallon MB. Hepatopulmonary Syndrome. Clin Liver Dis. 2014: 407-420.

PubMed: https://pubmed.ncbi.nlm.nih.gov/24679503/

3. Silva Júnior OC, Mazzetto SA, Souza MEJ, Picinato MANC, Sankarankutty AK. Obstrução Biliar Estra Hepática. In: Silva OC Zucoloto S, Beer A. Modelos Experimentais de Pesquisa em Cirurgia. São Paulo: Robe, 1998.

4. Oded B, Eyal S, Michael W, Zeev P, Malena CC, et al. Hepatopulmonary syndrome in patients with cystic fibrosis and liver disease. Chest. 2016 149: e35-e38.

PubMed: https://pubmed.ncbi.nlm.nih.gov/26867851/

5. Xu D, Chen B, Gu J, Chen L, Belguise K, et al. Inhibition of autophagy ameliorates pulmonary microvascular dilation and PMVECs excessive proliferation in rat experimental hepatopulmonary syndrome. Sci Rep. 2016; 30833.

6. Grilo-Bensusan I, Pascasio-Acevedo JM. Hepatopulmonary syndrome: $W$ what we know and what we would like to know. World $J$ Gastroenterol. 2016; 22: 5728-5741.

PubMed: https://pubmed.ncbi.nlm.nih.gov/27433086/

7. Tieppo J, Cuevas MJ, Vercelino R, Tuñón MJ, Marroni NP, et al Quercetin administration ameliorates pulmonary complications of cirrhosis in rats. J Nutr. 2009; 139: 1339-1346.

PubMed: https://pubmed.ncbi.nlm.nih.gov/19494027/

8. Rosa DPD, Bona S, Simonetto D, Zettler C, Marroni CA, et al. Melatonin protects the liver and erythrocytes against oxidative stress in cirrhotic rats. Arq Gastroenterol. 2010; 47: 72-78.

PubMed: https://pubmed.ncbi.nlm.nih.gov/20520979/

9. Tan DX, Manchester LC, Esteban-Zubero E, Zhou Zhou Z, Reiter RJ. Melatonin as a potent and inducible endogenous antioxidant: synthesis and metabolism. Molecules. 2015; 20: 18886-18906.

PubMed: https://pubmed.ncbi.nlm.nih.gov/26501252/

10. Colares JR, Schemitt EG, Hartmann RM, Licks F, Soares MC, et al. Antioxidant and anti-inflammatory action of melatonin in an experimental model of secondary biliary. World J Gastroenterol. 2016; 22: 8918-8928.

PubMed: https://pubmed.ncbi.nlm.nih.gov/27833383/

11. Tieppo J, Vercelino R, Dias AS, Silva Vaz MF, Silveira TR, et al. Evaluation of the protective effects of quercetin in the hepatopulmonary syndrome. Food Chem Toxicol. 2007; 45: 1140-1146. PubMed: https://pubmed.ncbi.nlm.nih.gov/17306429/

12. Li X, Chen Y, Wang L, Shang G, Zhang C, et al. Quercetin alleviates pulmonary angiogenesis in a rat model of hepatopulmonary syndrome. Braz J Med Biol Res. 2016; 49: e5326.

PubMed: https://pubmed.ncbi.nIm.nih.gov/27383124/
13. Vercelino R, Crespo I, de Souza GF, Cuevas MJ, de Oliveira MG, et al. $\mathrm{S}$-nitroso-N-acetylcysteine attenuates liver fibrosis in cirrhotic rats. J Mol Med. 2010; 88: 401-411.

PubMed: https://pubmed.ncbi.nlm.nih.gov/20062961/

14. Fernández A, Ordóñez R, Reiter RJ, González-Gallego J, Mauriz JL. Melatonin and endoplasmic reticulum stress: relation to autophagy and apoptosis. J Pineal Res. 2015; 59: 292-307.

PubMed: https://pubmed.ncbi.nlm.nih.gov/26201382/

15. Tomás-Zapico $C$, Coto-Montes A. A proposed mechanism to explain the stimulatory effect of melatonin on antioxidative enzymes. J Pineal Res. 2005; 39: 99-104.

PubMed: https://pubmed.ncbi.nlm.nih.gov/16098085/

16. Kountouras J, Billing BH, Scheuer PJ. Prolonged bile duct obstruction: a new experimental model for cirrhosis in the rat. $\mathrm{Br} J$ Exp Pathol. 1984; 65: 305-311.

PubMed: https://pubmed.ncbi.nlm.nih.gov/6743531/

17. Llesuy SF, Milei J, Molina H, Boveris A, Milei S. Comparison of lipid peroxidation and myocardial damage induced by adriamycin and 4'-epiadriamycin in mice. Tumori. 1985; 71: 241-249.

PubMed: https://pubmed.ncbi.nlm.nih.gov/3861023/

18. Buege JA, Aust SD. Microsomal lipid peroxidation. Methods Enzymol. 1978; 52: 302-310.

PubMed: https://pubmed.ncbi.nlm.nih.gov/672633/

19. Boveris A, Chance B. The mitochondrial generation of hydrogen peroxide. General properties and effect of hyperbaric oxygen. Biochem J. 1973; 134: 707-716.

PubMed: https://pubmed.ncbi.nlm.nih.gov/4749271/

20. Misra HP, Fridovich I. The role of superoxide anion in the autoxidation of epinephrine and a simple assay for superoxide dismutase. World J Biol Chem. 1972; 247: 3170-3175.

PubMed: https://pubmed.ncbi.nlm.nih.gov/4623845/

21. Flohe L, Gunzler WA. Assays of glutathione peroxidase. Methods Enzymol. 1984; 105: 114-121.

PubMed: https://pubmed.ncbi.nlm.nih.gov/6727659/

22. Mannervik B, Guthenberg C. Glutathione transferase (human placenta) Methods Enzymol. 1981; 77: 231-235.

PubMed: https://pubmed.ncbi.nlm.nih.gov/7329301/

23. Granger DL, Anstey NM, Miller WC, Weinberg JB. Measuring nitric oxide production in human clinical studies. Methods Enzymol. 1999;301:49-61. PubMed: https://pubmed.ncbi.nlm.nih.gov/9919553/

24. Sellares J, Loureiro H, Ferrer M, Amaro R, Farre R, et al. The effect of spontaneous breathing on systemic interleukin- 6 during ventilator weaning. Eur Respir J. 2012; 39: 654-660.

PubMed: https://pubmed.ncbi.nlm.nih.gov/21778161/

25. Laemmli U, Molbert E, Showe M, Kellenberger E. Form determining function of the genes required for the assembly of the head of bacteriophage T4. J Mol Biol. 1970; 49: 99-113. PubMed: https://pubmed.ncbi.nlm.nih.gov/5450520/

26. Towbin $\mathrm{H}$, Staehelin T, Gordon J. Eletrophoretic transfer of proteins from polyacrylamide gels to nitrocellulose sheets: procedure and some applications. Biotechnology. 1992; 24: 145-149.

27. Speit G, Hartmann A. The comet assay (single-cell gel test). A sensitive genotoxicity test for the detection of DNA damage and repair. Methods Mol Biol. 1999; 113: 203-212.

28. Picada JN, Flores DG, Zettler CG, Marroni NP, Roesler R, et al DNA damage in brain cells of mice treated with an oxidized form of apomorphine. Brain Res Mol Brain Res. 2003; 114: 80-85.

29. Tieppo J, Vercelino R, Dias AS, Marroni CA, Marroni N. Common bile duct ligation as a model of hepatopulmonary syndrome and oxidative stress. Arq Gastroenterol. 2005; 42: 244-248.

PubMed: https://pubmed.ncbi.nlm.nih.gov/16444380/ 
30. Comporti M, Signorini C, Arezzini B, Vecchio D, Monaco B, et al. F2isoprostanes are not just markers of oxidative stress. Free Radic Biol Med. 2008; 44: 247-256.

PubMed: https://pubmed.ncbi.nlm.nih.gov/17997380/

31. Mason RP, Walter MF, Mason PE. Effect of oxidative stress on membrane structure: small angle $\mathrm{X}$-ray diffraction analysis. Free Radic Biol Med. 1997; 23: 419-425.

PubMed: https://pubmed.ncbi.nlm.nih.gov/9214578/

32. Qiao D, Hou L, Liu X. Influence of intermittent anaerobic exercise on mouse physical endurance and antioxidant components. $\mathrm{Br} \mathrm{J}$ Sports Med. 2006; 40: 214-218.

PubMed: https://pubmed.ncbi.nlm.nih.gov/16505076/

33. Bona S, Filippin LI, Di Naso FC, David CD, Valiatti B, et al. Effect of antioxidant treatment on fibrogenesis in rats with carbon tetrachlorideinduced cirrhosis. ISRN Gastroenterol. 2012; 2012: 762920.

PubMed: https://pubmed.ncbi.nlm.nih.gov/22577570/

34. Brzozowski T, Jawoewk J. Basic and clinical aspects of melatonin in the gastrointestinal tract. New advancements and future perspectives. Curr Pharm Des. 2014; 20: 4785-4787.

PubMed: https://pubmed.ncbi.nlm.nih.gov/24251669/

35. Reiter RJ, Calvo JR, Karbownik M, Qi W, Tan DX. Melatonin and its relation to the immune system and inflammation. Ann N Y Acad Sci. 2000; 917: 376-386.

PubMed: https://pubmed.ncbi.nlm.nih.gov/11268363/

36. Schemitt EG. Ação da glutamina sobre o estresse oxidativo e processo inflamatório na insuficiência hepática aguda grave. Dissertação de mestrado. Universidade Federal do Rio Grande do Sul. 2014.

37. Feng $\mathrm{G}$, Rong $\mathrm{H}$. The role of hemodynamic and vasoactive substances on hepatopulmonary syndrome. Eur Rev Med Pharmacol Sci. 2014; 18: 380-386.

PubMed: https://pubmed.ncbi.nlm.nih.gov/24563438/
38. Waltz P, Escobar D, Botero AM, Zuckerbraun, BS. Nitrate/Nitrite as critical mediators to limit oxidative injury and inflammation. Antioxid Redox Signal. 2015; 23: 328-339.

PubMed: https://pubmed.ncbi.nlm.nih.gov/26140517/

39. Rodríguez-Roisin R, Krowka MJ, Hervé P, Fallon MB. ERS Task Force Pulmonary-Hepatic Vascular Disorders (PHD) Scientific Committee. Pulmonar-hepatic vascular disorders (PHD). Eur Respir J. 2004; 24: 861-880.

PubMed: https://pubmed.ncbi.nlm.nih.gov/15516683/

40. Mauriz JL, Collado PS, Veneroso C, Reiter RJ, González-Gallego J. A review of the molecular aspects of melatonin's anti-inflammatory actions: recent insights and new perspectives. J Pineal Res. 2013; 54: 1-14. PubMed: https://pubmed.ncbi.nlm.nih.gov/22725668/

41. Kunak CS, Ugan RA, Cadirci E, Karakus E, Polat B, et al. Nephroprotective potential of carnitine against glycerol and contrastinduced kidney injury in rats through modulation of oxidative stress, proinflammatory cytokines, and apoptosis. Br J Radiol. 2016; 89: 2-14. PubMed: https://pubmed.ncbi.nlm.nih.gov/26562095/

42. Krowka MJ. Hepatopulmonary syndrome: what are we learning from interventional radiology, liver transplantation, and other disorders? Gastroenterology. 1995; 109: 1009-1013.

PubMed: https://pubmed.ncbi.nlm.nih.gov/7657087/

43. VercelinoR,TieppoJ,DiasAS, etal.N-AcetylcysteineEffectson Genotoxic and Oxidative stress parameters in cirrhotic rats with hepatopulmonary syndrome. Basic Clin Pharmacol Toxicol. 2008; 102: 370-376. PubMed: https://pubmed.ncbi.nlm.nih.gov/18341514/

44. Bommena S, Gerkin RD, Agarwal S, Raevens S, Glassberg MK, et al. Diagnosis of Hepatopulmonary Syndrome in a Large Integrated Health System. Clin Gastroenterol Hepatol. 2020.

PubMed: https://pubmed.ncbi.nlm.nih.gov/33007510/ 